\title{
Semiotic Signs and Kui Performing Interpretation in the Paradigm of the National Concepts of Kazakh Music Pedagogy
}

\author{
Ainur Yessetova ${ }^{1}$, Gulnara Atembayeva ${ }^{1}$, Ainur Mashimbayeva ${ }^{1}$, Erbol Usenbayev $^{2}$, \\ Gulsara Absatarova ${ }^{1}$, Svetlana Janseitova, ${ }^{1, *}$ \\ ${ }^{1}$ Department of Social and Humanitarian Disciplines, Kazakh National Conservatory named after Kurmangazy, \\ Almaty, 50000, Kazakhstan \\ ${ }^{2}$ Department of Musical Education, Kazakh National Conservatory named after Kurmangazy, Almaty, 50000, Kazakhstan
}

Received August 18, 2020; Revised October 10, 2020; Accepted October 24, 2020

\section{Cite This Paper in the following Citation Styles}

(a): [1] Ainur Yessetova, Gulnara Atembayeva, Ainur Mashimbayeva, Erbol Usenbayev, Gulsara Absatarova, Svetlana Janseitova, "Semiotic Signs and Kui Performing Interpretation in the Paradigm of the National Concepts of Kazakh Music Pedagogy," Universal Journal of Educational Research, Vol. 8, No. 11B, pp. 6192 - 6199, 2020. DOI: 10.13189/ujer.2020.082257.

(b): Ainur Yessetova, Gulnara Atembayeva, Ainur Mashimbayeva, Erbol Usenbayev, Gulsara Absatarova, Svetlana Janseitova (2020). Semiotic Signs and Kui Performing Interpretation in the Paradigm of the National Concepts of Kazakh Music Pedagogy. Universal Journal of Educational Research, 8(11B), 6192 - 6199. DOI: 10.13189/ujer.2020.082257.

Copyright $\bigcirc 2020$ by authors, all rights reserved. Authors agree that this article remains permanently open access under the terms of the Creative Commons Attribution License 4.0 International License

\begin{abstract}
The content of music education and upbringing oriented towards the national music tradition belongs to the basic laws of modern music education. These are objective reasons that characterize the essential connection between social and musical phenomena or processes, without which one cannot effectively implement music education and upbringing. This article is dedicated to the study of a special style of playing stringed instruments in the performance of kuis, Kazakh instrumental musical compositions. The interpretation of archetypal ethnical texts evoked an organic syncresis of music with an ancient sign language, including a separate aspect associated with the specifics of non-verbal forms of artistic communication. The essence of the sign language of Kazakh kuis, its meaning and the limits to its applicability are not fully disclosed. They require considering many issues related to the semantic nature of gestures. The present study is based on the exploration of performing Kazakh kuis with stressing on gestures as semiotic structures on these ethnical Kazakh compositions. The authors adhere to the principle that musical language is a synergy of word (text), music and its performing (gestures). The study used comparative-historical, theoretical, and historical-typological methods.
\end{abstract}

Keywords Emotionality, Expressiveness, Kui, Gesture, Sign System, Modality, Sensory Perception, Music Pedagogy, National Music

\section{Introduction}

The formation of the categorical essence of "music pedagogy" as a branch of scientific knowledge took place in the historiography of music pedagogy in a dialectical relationship with the development of modern pedagogical thought, revealing the essence of its components (education and development). Music uses sign language as a sign system, without which one cannot achieve a real high quality and expressive sound. The search for effective ways of music education is facilitated by theoretical research in pedagogy, psychology, and musicology. An important role in the formation of strong foundations of music pedagogy is played by a thorough study of national music traditions, in particular, traditional folk texts and the peculiarities of their performance. Kui is a Kipchak instrumental musical composition performed with national plucked, bow and wind instruments such as 
Dombyra, Qobyz, and Syrnai. In Kazakh culture, kuis were learned by heart and passed from generation to generation without written fixation. For example, Kazakh folk kui "aqsaq qulan" (lame onager) is dated to the 13th century. Authors of many famous Kazakh kuis lived in the Middle Ages. But the pick of the culture comes to the 19th and 20th centuries [1-2].

A particular role in performing musical compositions is played by gestures, especially while speaking about kuis as Kazakh national heritage. Accompanying and illustrating the music, gestures take on the role of a "remark", aimed at a mutual understanding between the musician and the audience; "they expressed what the word is powerless to say" [3]. Gesture, which is not a sound, represents the real objectivity of a sound, associated with its visual perception, and "reproduces the physical realization of musical ideas" [4]. Its perception invariably constitutes "a fundamental part of music and what is fully perceived as music" [5]. The other definitions and characteristics of gestures include: "bodily choreography", "body language" [6], "bodily metaphor of sound", "bodily ideograms"; a special "physical language based on signs instead of words" [7]; a wonderful "field of expression" [8]; a code implementing successful communication, growing in the soil of affect and feelings; thoughts and forms, endowed with unconscious motivation [9]. The link between the inner world (consciousness) and the outer world (physical world), causing a rich range of creative reactions to feelings, conveys the internal movements of the soul [10], performs associative communication between the performer and the audience, and fulfils regulatory, expressive, communicative, artistic, and aesthetic functions.

The article is composed of the following sections: Materials and Methods (describing what studies are related to the topic, the state of novelty of the presented theme, etc.); Literature Review (a brief overview of studies on the topic of music as a semiotic sign, gestures theory, etc.); Results (presenting the main achievements of the present study); Discussion (discussing the results of the study); and Conclusion, proceeded with a full reference list.

\section{Materials and Methods}

The semiotic approach to the music field was developed in the 20th century. For the first time, linguistic analysis was applied to music in the early 20th century, but it spread only in the late 20 th - early 21 st century. The use of linguistics in a non-linguistic environment was first mentioned by F. de Saussure in 1916. In the present work, we applied the concept of semiology - a general science of signs (studying the life of signs within the framework of the life of society; the science of "signs and what laws they are governed by"). Further studies set the task of determining the validity of F. de Saussure's approach as the main one in semiotics. The main results can be formulated as follows: if music, like language, is a linear system (that is, developing in chronological order), then it has two dimensions.

When identifying the symbolic nature of non-verbal gestures, we used some aspects of the semiotic approach. It allowed determining the rules for the development of signs and their combinations (syntax), establishing the semantic content of gesture signs (semantics), as well as identifying conditions under which certain sign situations occur (pragmatics), and the effectiveness of sign communication associated with emotionality.

The semiotic structure of musical compositions was studied by Ahlner \& Zlatev [11], Lazutina \& Lazutin [12], Monelle [13], Spychiger [14], Tarasti [15], and Turino [16]. Although they presented a profound notion as for the interrelations of music and semiotics, the peculiarities of the national interpretation of the general concept require close attention and theoretical and practical investigations.

The works of R. Birdwhistell, G.E. Kreidlin, Y.M. Lotman, M.S. Kagan, E.Y. Basin, C.K. Rapport, M.G. Aranovsky, Y. Kristivaya, P. Oleron, L.O Reznik, T.V. Lazutin, E. Sapir, A. Arto, and the psychological works of L.S. Vygotsky, A.N. Leontyev helped analyze gestures as a specific code and a sign system, which is necessary for successful communication.

The video recordings of the concert performances of professional kui artists such as Karshiga Akhmediarov, Dina Nurpeisova, Jambyl Jabaev, Garifulla Kurmangaliev, and others, who performed kui compositions in a vivid, virtuosic and psychologically tense manner, using sign language as a component of interpersonal communication, were used as a material in the present study.

This research is based on comparative-historical, theoretical, and historical-typological methods, as well as on the works of B. Amanov, A. Seidimbek, P. Shegebaev, T. Asemkulov, B. Jusipov, and other authors, associated with Kazakh instrumental music, and the analysis of the peculiarities of Zhetisu, Altay, Karatau, Syr Darya, Mangystau, Aktobe, and Arka performance schools. While considering semiotic signs and kui performing interpretation, music culture can be viewed as a certain musical semiosphere, reflecting the peculiarities of the creation, perception, reproduction, and transmission of musical symbols in culture. The aim of the study is to conduct research on semiotic signs and kui performing interpretation in the paradigm of the national concepts of Kazakh music pedagogy. This article makes an attempt to analyze Kazakh kuis in the paradigm of semiotic signs as the main elements of musical language and their specific role in the performance of these folk lyrics.

To carry out a theoretical study, a scientific comprehensive approach was taken as fundamental, including an analysis of musicological, informational, communicative, semiotic, semantic, and 
psychophysiological components. It contributed to disclosing the logic of using sign language in the creative process, understanding the psychological, technical, and methodical possibilities of the creation of a musical image and the analysis of professional performance, teaching practice, monitoring the colleagues and older generation's performance activities, and presenting a synthesis and generalization of the research results. This approach with the use of semiotic vectors will help organize the learning environment more effectively during the study of Kazakh national culture and give a more complete interpretation of the archetypal, sacred content of Kazakh folk music.

\section{Literature Review}

Music culture, as a "local" semiotic system functions, as a part of the general semiotic system of culture. Music is an indispensable part of everyday life, an element of the environment, in which every member of society lives from the moment of birth and gradually becomes part of it. This environment influences people, shaping their minds and cultivating certain sensory, motor and other abilities, just as genetic inheritance determines their physical structure. The characteristic sounds of "own" voices and instruments, "own" melodies, rhythms and timbres, singing and playing manners, dance movements and gestures - all this is absorbed, assimilated and mastered practically like sounds, words, and grammatical structures of the language. In this regard, the study of the deep genetic, essential, symbolic foundations of the musical phenomenon is becoming the most urgent problem of modern philosophical and cultural knowledge. The need to resolve this problem is associated with a departure from the usual paradigms and stereotypes in the musical field, as well as with the need to develop musical aesthetics and semiotics and consider music in terms of language.

The main place in the semiotics of culture is given to the text. The well-organized text that has a set of signs with a certain structure in accordance with the rules of the language can generate a meaning [17]. Many research studies consider gestures not as a ready, available message, but as "the process of formulation of a message (a traceable process); it is a work that precedes the creation of a sign (meaning) in the course of communication" [18]; the sign is used in many spheres of activity, being "an instrument of human knowledge and a means of communication" [19]; it accords with "a parallel sound; sign language is formed by the closest and most usual unity of a special kind of symbolic facial expressions and sound" [20]; along with the culture of words, there is also a culture of gestures [21]; the intensity of the experience "puts the thought into words; an emotional word is expressed with intonation, which expands into facial expression and gesture" [22]; to convey various "modalities of discourse, we need a kinetic speech" [23].
In the style of delivering music, developed by a certain epoch, the sign system is used as a multi-channel structure of the communication system, which "unites with art, decorates it and becomes its integral part" [24].

The theoretical basis of the study is formed by the works of researchers on the semiotic structure of musical compositions. Tarasti $[15,25]$ developed a semiotic theory and analysis of music in the united paradigm of semiotics and myth. Ahlner \& Zlatev [11] studied the cognitive semiotic approach to sound symbolism. Lazutina \& Lazutin [12] and Monelle [13] contributed to the fundamental notions of understanding the language of music as a specific semiotic structure. Spychiger [14] paid attention to the understanding of musical activity and musical learning as sign processes in the context of the semiotic approach to music education. Turino [16] dedicated his work to the signs of imagination, identity, and experience in the scientific framework of a Percian semiotic theory for music.

\section{Results}

Musicians use two types of gestures: technical and expressive. Technical gestures are used to obtain (extract) sound and overcome mechanical (technical) problems arising in the performance process. Distinct and unique gestures in Kazakh music have no analogues in the world literature. They are taken as not only an artistic value, satisfying purely aesthetic needs of the ethnic group, but also as the structuring music core. This allows us to consider them as a world-modelling element that can significantly determine the worldview in Kazakh music.

Nomads used sign language when tracking a beast. Any sound that did not meet any objects that could absorb it on its way in a steppe was easily heard from afar. Battues required the development of a special system of gestures, so as not to scare the animals. Having achieved a high degree of development, both in terms of the abundance of lexemes and structural organization, the comparative vocabulary of nomads testifies to a rather deep connection between the Amerindian and Turkic verbal languages. These similarities make it possible to assert that Sioux, Maya, and Turkic are cognate languages and to reveal the kinship of the Turks (Kazakhs, Kyrgyz, Tuvans, etc.) with some Indian tribes [26]. Turkic tribes, who left for America through the Bering Strait several thousand years ago, preserved the hunting and military proto-language of gestures, developing it to the level of verbal language.

In the culture of Eurasian nomads, sign language disappeared in connection with the fall of the Turkic empires and states, which led to the degradation of such aspects of culture as battues, large-scale military operations. It is difficult to describe the sign language that conveys feelings and symbolic positions and poses. This difficulty lies in the study of musical gestures, their 
productive beginning, key positions, static elements, including such oppositions as tension/relaxation, speed/slowness, discontinuity/smoothness, etc.

Analysis of the functional characteristics of the motor apparatus, its fixation and codification in the performance process made it possible to identify the semantic fill rate, the external intuitive vision of the corporal image, and the parameters of the pulsation occurring on the verge of mental and physical spheres. It also allowed us to consider gesture as specific sheet music that controls and edits the process, to identify the qualitative characteristics of expressiveness, their constituent modalities and "tension" of energy, to consider performing activities on a personal and psychological level, to determine the levels of the artistic structure (longitudinal, dynamic, agogical, pitch, timbre characteristics) with their specific figurative features and stylistic shades, as well as to consider the physical and temporal concentration of gestures "ideograms" (Meyerhold's term) in plastic sequence, arising from affect and feelings.

Considering the musical semantics of gestures as an intonation, based on B.V. Asafiev's semiotic approach to music, we concluded that it consists in the expression of feelings and thoughts. Determined by "mental breath" and rhythm, gestures become "an imaginable intonation" [27]. The visual element, consisting of two types, is equally important. The first type is a statistic image representing the fixed position of the articulation apparatus of the right hand, controlling the real sound. The most common are dynamic images, deployed due to changes in the spatial position of the sound-producing apparatus in time.

The amplitude and range of right-hand gesture movements used by kui musicians have not only an illustrative and figurative nature but also an ornamental nature. Inconspicuous gesture ideograms, being structurally complete, participate in the sound production process. Aside from the fingers, hand and forearm, this process may involve strokes with the entire arm and shoulder. Right-hand gesture movements may be divided into the main groups. These are strokes with the participation of the shoulder consisting of two types: a simple stroke and a stroke with a swinging hand; when the musician raises his wrist above the shoulder, far above his head before hitting the strings. In both types, the fingers abruptly hit the strings. These sound production methods have a direct impact on the strength and character of the sound. The following group includes the ornamental movements of the wrist and fingers: the performer does these movements while swinging the arm before he hits the strings; the wrist moves over the fret board, not touching the strings, imitating a stroke, a light touch.

Gesture movements are used to achieve a greater effect (the palm, initially facing the performer, gradually turns up). The hand moves upward and slightly to the left, meanwhile the degree of external activity and intension of gestures also increases (the right hand extends the amplitude of gestures, increasing the intensity). Then the wrist makes the inverse process, gradually moving from a higher plane (where it was before producing the sound) to a lower plane. The palm gradually turns to the public. In each change in the dynamics of gestures, we observe the strengthening or weakening of emotions, brightness and saturation of the musical style, and dynamic shades. There are different wrist movements above the upper deck of the dombra, clicking on the upper deck, clicking and hitting the bottom deck; sometimes the dombra is turned round during the performance, raised above the head, or placed vertically on the knee.

Depending on tonal characteristics, musicians perform kuis at a slow pace in big, medium, and small amplitudes, reflecting an important character-building phrase in the "bodily metaphor of sound". Small amplitude gestures are used in fast tempo music. These gestures are small in form, structurally complete kui fragments, and used to play up the melodic formulae.

Sign language requires professional skills and observation. Evoking the audience's delight, it bears an exclusively national character. By analyzing the characteristics of the performance of various kui interpretations, we were able to consider the semantics of gestures, determine them as a unique cultural phenomenon, and reveal their aesthetic content. For this purpose, we used archival materials, preserved gramophone recordings, audiotapes of T. Mergaliev, A. Janbyrshin, B. Yskakov, A. Toktagan, J. Juzbaev, D. Bekenov, K. Saizhanov, E. Nurymbetov, and other performers' kuis. We also relied on the documents preserved in the folklore laboratory of Kurmangazy Kazakh National Conservatory and the archives of Kazakh kui researchers such as A. Raimbergenov, S. Medeubek, T. Tokjan, J. Juzbaev, and B. Bekmukhamedov, who had provided video materials of kui and legend performances. In the present study, we focus on the kuis "Okhota" (Hunting), "Tolkyn" (Wave), "Aksak qulan" (Lame kulan), "Akku" (Swan), "Nar idirgen" (Milking a camel), which are based on industrial and hunting magic.

The kui "Maral" is replete with gesture elements. The play of hands conveys delay, handhold, glide over the strings, and other performance characteristics. Living in a single stream of cosmic time and guided by the measure as the basis for understanding the world, nomads preserved their harmonious relations with nature. For example, the number of kulans and saigas was regulated by special hunting rules and determined by the concept of "take no more than necessary", "do not kill animals for fun", and it was forbidden to hunt during the childbearing and lactation period. We can see the gestures reminding of those of deaf-mutes in slow motion: the index finger pointing up - 'I see a deer'; the thumb and index finger forming a circle - 'I see female deer near'; the soft wrist rotation that resembles the round shape of the hip and belly - 'the female deer is pregnant'; four fingers are 
clenched and lowered down, moving to the right and left 'shooting is prohibited'. Each set of gestures contributes to the creation and understanding of the artistic image. The technique of kui performance includes cross-play, cut, undulations with the right hand along the dombra neck: 'mepin mapmy' (plucking), 'iлin mapmy' (pinching), 'mepic mapmy' (up-strokes), an expressive acting technique - pointing, waving the hand, hints shown with parts of the body.

The kui "Tolkyn," performed by the dombra player M. Ongarov, uses the following techniques: 'сол қолмен іліп mapmy' (pinching with the left hand), 'cyüpemin mapmy' (dragging the fingers on the strings), 'opan mapmy' (wrapping movements); a smooth wave-like swing of the wrist to the right and left, a colorful inter-semitone slide from one tone to another. The raised hand with the fingers easily and gracefully opening and forming the shape of a fan, in the direction of the hand, signifies 'a swift cast of the net'; an abrupt thrust of the wrist up and down - 'fish rampaging in the net' - this movement conveys an emotional outburst, joy at the sight of plenty of fish; the hand going down with some tension, clenching the fan-shaped fingers - 'pulling the net with force'. These gestures are characterized by expressive transitions, enhancing the intonational development of the kui.

The kui "Aksak qulan" is based on a legend, tracing its origin to ceremonial hunting for totem animals. This is a classic 'estirtu' - an allegorical message about death: "Jochi khan's only son loved hunting for kulans. Father knew it was dangerous, and he wouldn't let his son go hunting alone, but one day his son disobeyed and secretly left for hunting. He met a herd of kulans and started shooting them. Arrows hit the kulans and they fell one by one to the ground. In excitement, he did not notice that he had used all the arrows. Sensing that the khan's son was left unarmed, the leader of the herd, a lame kulan, killed the young man with a kick. After finding out that his son had disappeared, the khan announced that anyone who dared to report the death of his son would be killed by pouring the molten tin into the mouth. After that, no one dared to inform the khan of the tragic death of his son. One day, one of the servants reported that someone who knew about his son's death wanted to see the khan. The khan ordered to let him in. A man, who was a dombra player, entered. The khan asked to lay the case before him. Here the musician picked up the instrument, having said: "My dombra will tell you everything", - he started playing a kui. In the beginning of the kui, the musician artfully depicted a galloping horse. It made the khan think that his son was coming home. A smile passed over his face. At that moment, the dombra player proceeded to the ominous topic of fate: the dombra started crying. The khan dropped his head on his chest feeling something bad had happened. Hope gave way to a heavy premonition. The musician depicted the joy of the khan's son at the sight of a herd of kulans, then the whistle of arrows cutting through the air, and the clatter of galloping kulans. Unfortunately, the khan understood the language of music very well. The dombra player reached the culmination of the kui - the dombra now made a sound similar to a howl of despair, dying breath of a person. The khan jumped up, biting his lip. He clenched his fists, and his eyes were bloodshot. Meanwhile, the kui player returned to the original topic of fate, which sounded restful sadness and ended with barely audible notes, depicting the regret of a soul leaving this world. The khan covered his face with his hands, wet with tears. Quickly mastering himself, he wished his will to be fulfilled: "Dombra, you announced the death of my beloved son. You will be punished for that!" And he ordered to pour the molten tin into the hole on the deck of the dombra so that it would be silenced forever".

Up to the middle of the 20th century, Kazakh shamans played various musical instruments to treat animals. Legends about such treatment with the help of music reflect nomads' ideas about the possibilities of instrumental music. The legend "Milking a Camel" tells this story: "In ancient times there lived one person who had a camel. It was a female camel and one day she gave birth to a colt, but unfortunately, in a few days this colt died. According to Kazakh tradition, the man stripped the skin off the dead colt and stuffed it with a straw to make the camel think that the colt was alive. However, this didn't help mislead the camel. She was driven out to graze many times, but she kept coming home and looking for her colt. Her milk supply dropped from her grief and stress, which caused the danger of starvation to the whole family."

One day the man came out of the house and saw the camel with tears spilling out of her eyes. There was a man named Auelbek who lived in the same village. The man went to him for advice. Auelbek said: "Only music can save your camel. Only a great musician and a good dombra player can make her give milk. You should gather the best performers and give a big reward to the one who helps the camel". The man replied: "If I meet a musician who can affect a camel with his art, I will give my only daughter to such a master!"

The news quickly spread to the steppe. Many dombra players started coming to try their skills, but the camel still would not give milk: "The girl tied the camel near the well, put a bucket and prepared to milk. An old man came first and started playing the dombra. The aksakal's dombra gently started calling the camel with the sound "kaus, kaus", and then started crying imitating the voice of a camel. Blood ran hot in the camel's all 62 veins, and her udder filled with milk. The girl felt that and firmly squeezed the udder, saying: - No milk! Pass the dombra to another man!" She cheated because she did not want to marry an old man. A young dzhigit was next to play the dombra. Wishing to cover up a lie, the girl began to milk a camel only when the young musician had played a part of the kui. The aksakal realized that the girl had cheated; but 
having remembered about his old age, he started playing the kui "I'm past my prime" with a sad heart. Only a true master with the power of his art could make the camel give milk again. According to a legend, the old man's kui, which imitated the voice of a camel, had a sacred power of influence on the sacred animal. The rhythmic pattern of two fingers bent as if pulling the strings repeated several times in the kui: it depicted the milking process, devoid of splendor dramatic pathos. The movements were elegant and gentle, with no abruptness; the wrist movements were restrained and accurate, and they gently and precisely conveyed the subtle vibrations. The kui was played by the dombra player N. Jalynbetov.

The psychological concept of the worldview by A.N Leontiev, which makes it possible to develop and structure a typology of the performer's worldview, his impression content, is highly useful for the present study [28]. The lexical, conceptual, and categorical analysis of gesture movements showed that the expressive and emotional style of the musician is determined by the set of figurative signs peculiar to him: "Movement", "Space", "Experience", "Sonority", "Behavior" and others, embodied in the appropriate ways of musical pronunciation. At the level of perception, they all act systematically, in a special integral unity specific for the musician [29-31]. To define gesture movements, we used a set of concepts derived from the analysis of conceptual and categorical fields. These concepts contribute to the elaboration and specification of analytical categories, "worldviews". This method will allow deducing the following characteristics of gesture movements (Table 1).

Analysis of stylistic and gesture movements allowed us to consider the main features of stylistic elements and distribute them into the following categories: "Worldview" (as integrity) - harmonious; "Character," manifested in the unity of the properties of behavior, communication, action, experience, - contemplative, delicate; "Behavior" - explosive, exceptional; "Communication" - intimate, tender, witty (styles); "Thinking" - polemical, witty; "Experience" - gentle, sad, emotional, expressive; "Perception, sensation" - sensitive, gentle, delicate; "Sonority" - quiet, imitating the timbre; "Movement" flexible, emotional, balanced; "Objectivity" - picturesque, figural, psychological, and characteristic; "Spatiality" aerial, plastic.

The conceptual and categorical analysis of sign language showed that the performer's expressive and speech style is determined by the set of figurative signs peculiar to him, including "movement", "space", "experience", "sonority", "behavior", expressed in gesture movements and embodied in the appropriate methods of musical pronunciation.

Table 1. Characteristics of gesture movements

\begin{tabular}{|c|c|c|c|}
\hline & Style & & Dynamics \\
\hline 1. & 'ritually gentle, flexible, sensually-gentle'; & 1. & 'wide, delicately sensual'; \\
\hline 2. & 'delicately gentle, emotionally and plastically flexible'; & 2. & 'wide, emotional'; \\
\hline 3. & 'sensually psychological, motorial and figural'; & 3. & 'contrastively emotional, delicate'; \\
\hline 4. & 'plastical, emotional and motorial'; & 4. & 'moderately quiet, emotional'; \\
\hline 5. & 'eloquent'; & 5. & 'contrastively emotional'; \\
\hline 6. & 'picturesque and psychological, sad and tender'; & 6. & 'quiet, expressive'; \\
\hline 7. & 'psychological, motor, volitional'; & 7. & $\begin{array}{c}\text { 'wide, emotionally sophisticated, with an intensifying } \\
\text { crescendo'; }\end{array}$ \\
\hline 8. & 'psychological, gentle, emotionally and plastically flexible'; & 8. & 'contrastive and expressive'; \\
\hline 9. & 'picturesque, emotional and motorial'; & 9. & 'wide, linear'; \\
\hline 10. & 'mythological, motorial and plastical'; & 10. & 'contrastive and linear, smooth'; \\
\hline 11. & 'capriciously refined'; & 11. & 'wide, sensitively subtle'; \\
\hline 12. & 'humorous'; & 12. & 'wide, sensitively subtle'; \\
\hline 13. & $\begin{array}{l}\text { 'picturesquely psychological, melancholic, motorial and } \\
\text { plastical'; }\end{array}$ & 13. & 'moderately quiet, expressive'; \\
\hline 14. & 'temperamental, tenderly passionate, energetically motorial'; & 14. & 'wide, expressive'; \\
\hline 15. & 'sensually psychological, gentle'; & 15. & 'emotionally and plastically flexible'; \\
\hline 16. & 'exquisitely gentle, emotionally and plastically flexible'; & 16. & 'wide, sensitively delicate'; \\
\hline 17. & 'psychological, gentle'; & 17. & 'moderately quiet, expressive'; \\
\hline 18. & 'witty'; & 18. & 'contrastively sophisticated'; \\
\hline 19. & 'playfully gentle, emotional and motorial'; & 19. & 'moderately quiet, emotional'; \\
\hline 20. & 'picturesquely aerial, sad and gentle'; & 20. & 'quiet, subtly sensitive, plastical'; \\
\hline 21. & 'virtuosic, with toccata features and motorial' & 21. & 'wide, sensitively linear'; \\
\hline 22. & 'decoratively elegant'; & 22. & 'emotionally sophisticated'. \\
\hline
\end{tabular}




\section{Discussion}

In ethno-cultural traditions and spiritual values, sign language has always occupied a special place because it carries the "knowledge of ancestors". As a unique substance, its importance in Kazakh music and culture is great and undeniable.

The study of sign language can be concluded that music has a certain set of artistic means, including gestures and bodily movement signs, which can convey and interpret the content of the musical work, as well as accompany the sound with the help of a special sign system. A performance activity, which is a kind of mediator between the musician and the audience, conveys the idea of the work, delivering aesthetic information from the performer to the public through a system of musical gestures. With the help of specific mechanisms of influence, called "gestural techniques" in musicology, and plastic movements, a performance activity takes on the role of "mute intonation" (B. Asafiev's term), the non-verbal form of communication, through which the sounding matter has an overpowering influence on the listeners. At the heart of the integral perception of music lies synaesthesia - co-sensation, representing the associative connection between auditory and visual sensations. Sounding before visual and artistic impressions, "synaesthesia largely enhances, complements and enriches the subsequent auditory sensations" [29].

The presented classification of gestures is based on the following functions: 1) affective and communicative functions, presented in the emotive function (expression of feelings, will, desires, and other states); 2) expression of the processes (perceptual, mnemonic, intellectual); 3) modal (expression of relation, position, evaluation, objects, self, subjects); 4) regulatory and communicative functions, realized in the actual gestures (making contact); 5) connotative (maintaining and reinforcing the contact); 6) "terminative" (end of contact); 7) incentive (activation); 8) informative and communicative functions, expressed in the presentation of information about oneself and the work.

\section{Conclusions}

Music pedagogy is an independent branch of art pedagogy in the system of general pedagogical theory. Based on the appropriate methodology, through the multicomponent (scientific-methodical, didactic, communicative, performing, creative) functionality of any music school, it is subjectively aimed at the musical upbringing and education of each person in the process of creative activity for self-realization, taking into account specific musical and social experience. The music pedagogy of any separate folk is impossible without a comprehensive study of national music traditions. For
Kazakh folk, kui, as a national music genre, plays an incredible role. In this study, we made an effort to unravel the mystery of the widespread use of gestures in kuis and to determine the specific understanding and application of gestures in instrumental art. An essential condition for the "reliability" of the performer's interpretation is the awareness of gesture movements along with the figurative and aesthetic spheres of their application and the peculiarities of interpretation. Musical gestures, as thoughtful forms and images with independent meaning, appear during an instantaneous performance. They are the essential parts of the performance affecting the perception and understanding of the structural form by the listener. As a skillful diamond-cutter, a musician polishes every gesture, adding luster and shine to them. Filled with the performances of "live" intonational sound and modalities, kuis become "breathful", expressive, and naturally emotional due to sign language.

This article opens up prospects for (1) the study of the issues of describing other types of sign language, semantics, and pragmatics, (2) the comparative study of sign language in the context of multi-structural languages, and (3) the study and determination of the roles of non-verbal components in the communicative interaction of the subjects of musical discourse. The results of the study can be used in the disciplines "History of Kazakh Music", "Ethno Solfeggio", "History of the Performing Arts," and contribute to the revival of this layer of traditional culture as unique art.

\section{REFERENCES}

[1] Alekseeva, L.A., Zh. Nazhmedenov, "Uniqueness of the Kazakh dombyra sound and tuning. Kazakh Culture researches", Scientific articles brochure, Almaty, 2000, pp. 34-54.

[2] Tansuğ, F., "A Bibliographic Survey of Kazakh and Kyrgyz Literature on Music", Yearbook for Traditional Music, vol. 41, pp. 199-220, 2009.

[3] Fokin, M., "Upstream", Iskusstvo, Leningrad, 1989, pp. $1-267$.

[4] Klark, Ye., "Understanding the psychology of performance gesture", in J. Rink (ed.), Musical Performance: A Guide to Understanding, Cambridge University Press, Cambridge, 2002, pp.76-97.

[5] Bowman, W., "Cognition and the body: Perspectives from music education", in L. Bresler (ed.), Knowing Bodies, Moving Minds, Kluwer Academic Publisher, Dordrecht, 2004, pp.127-178.

[6] Munch, Ch., "I Am a Conductor. Translated from French", $3^{\text {rd }}$ edition, Muzyka, Moscow, 1982, pp. 1-187.

[7] Chaffin, R., Lemieux A., C. Chen, "It is different each time I play: Variability in highly prepared musical performance 
gesture”, Music Perception, vol. 24, pp. 455-472, 2007.

[8] Caen, E., "Elements of conducting art. Translated from English”, Leningrad: Muzyka, 1980, pp. 1-163.

[9] Hatten, R.S., "Interpreting Musical Gestures, Topics, and Tropes: Mozart, Beethoven, Schubert", Indiana University Press, Bloomington, 2014, pp. 67-123.

[10] Munoz, E.E., "When gesture sounds: Bodily significance in musical performance", in A. Williamon, \& D. Coimbra (Eds.), International Symposium on Performance Science, European Association of Conservatoires (AEC), Utrecht, 2007, pp. 45-56.

[11] Ahlner, F., J. Zlatev, "Cross-modal iconicity: A cognitive semiotic approach to sound symbolism", Sign Systems Studies, vol. 38, pp. 298-348, 2010.

[12] Lazutina, T.V., N.K. Lazutin, "The Language of Music as a Specific Semiotic Structure. Asian Social Science, vol. 11, no. 7, pp. 201-207, 2015.

[13] Monelle, R., "Linguistics and Semiotics in Music", Routledge. Taylor \& Francis Group, London \& New York, 2014, pp. 15-79.

[14] Spychiger, M., "Understanding Musical Activity and Musical Learning as Sign Processes: Toward a Semiotic Approach to Music Education", Journal of Aesthetic Education, vol. 35, no. 1, pp. 53-67, 2001.

[15] Tarasti, E., "Musical Signification: Essays in the Semiotic Theory and Analysis of Music", Walter de Gruyter, Berlin, 2011, pp. 11-68.

[16] Turino, Th., "Signs of Imagination, Identity, and Experience: A Percian Semiotic Theory for Music", Ethnomusicology, vol. 43, no. 2, pp. 221-236, 1999.

[17] Lotman, Y.M., "The Structure of the Artistic Text", Iskusstvo, Moscow, 1970, pp. 1-192.

[18] Kristeva, Y., "Selected works: The destruction of poetics. Gesture: practice or communication?", Science, Moscow, 2004, pp.71-119.

[19] Reznikov, L.O., "Epistemological issues of semiotics”, LSU publishing house, Leningrad, 1964, pp. 14-59.

[20] Nietzsche, F., "Dionysian Worldview", Science, Moscow, 1870, pp. 1-198.

[21] Ershov, P.M., "The logic of passion and feelings in gestures", Moscow, Phoenix, 2009, pp. 1-192.

[22] Bonfeld, M.Sh., "Music: language, speech, thinking. Experience of systemic research of musical art", Mind, Saint Petersburg, 2006, pp. 45-86.

[23] Zaporozhets, A.V., "Perception, movement, action", Journal of Russian and East European Psychology, vol. 40, no. 4, pp. 53-93, 2002

[24] Ursom, J.O., "The ethics of musical performance", in M. Krausz (ed.), The Interpretation of Music: Philosophical Essays, Oxford University Press, Oxford, 1993, pp. 34-65.

[25] Tarasti, E., "Myth and Music: A Semiotic Approach to the Aesthetics of Myth in Music especially that of Wagner, Sibelius and Stravinsky", Walter de Gruyter, Berlin, 2012, pp. 35-67.

[26] Vinogradov, V., "Kyrgyz folk music", Kyrgysizdat, Frunze, 1958, pp. 1-123.

[27] Asafiev, B.V., "Musical form as a process", Science, Moscow, 1971, pp. 1-154.

[28] Leontiev, A.N., "Sensations and perception as images of the subject world. Cognitive processes: Sensations. Perception", Pedagogics, Moscow, 1982, pp. 1-139.

[29] Snyder, B., "Music and Memory", MIT Press, Cambridge, 2010, pp. 1-320.

[30] Özkut, B., Kaya, S.O., "Perceptions of Pre-school Teachers in Terms of Music Culture", Universal Journal of Educational Research, vol. 7, no. 1, pp. 278- 292, 2019. DOI: 10.13189/ujer.2019.070136.

[31] Yegul, B.U., "Determination of Preservice Preschool Teachers' Perceptions of Music Lesson through Metaphors", Universal Journal of Educational Research, vol. 6, no. 6, pp. 1305-1312, 2018. DOI: 10.13189/ujer.2018.060621. 